\title{
Flow-batch digital image colorimetric system to zinc oxide determination in ointments
}

aUniversidade Federal de Alagoas, Instituto de Química e Biotecnologia, Campus A. C. Simões, CEP 57072-970, Maceió-AL, Brazil.

'Instituto Federal de Educação Ciência e Tecnologia do Sertão Pernambucano, Campus Salgueiro, CEP 56000-000, Salgueiro-PE, Brazil.

'Universidade Federal da Paraíba, Departamento de Química, Campus I, CEP 58051-970, João Pessoa-PB, Brazil.

*E-mail: wellington@ ccen.ufpb.br

Recebido: 7 de Outubro de 2020

Aceito: 17 de Março de 2021

Publicado online: 17 de Maio de 2021

\section{Sistema Colorimétrico por Imagens Digitais em Fluxo-Batelada para Determinação de Óxido de Zinco em Pomadas}

Francisco Antônio da Silva Cunha, ${ }^{a}$ Pedro Lemos de Almeida Junior, ${ }^{b}$ Julys Pablo Atayde Fernandes, ${ }^{c}$ Luciano Farias de Almeida, ${ }^{c}$ Mario Cesar Ugulino de Araújo, ${ }^{c}$ Wellington da Silva Lyra, c,*iD

This work proposes a rapid, sensitive and accurate flow-batch digital image colorimetric (FB-DIC) system to zinc oxid determination in ointments. The method was based on the reaction between $\mathrm{Zn}$ (II) ions and zincon at $\mathrm{pH}=9.0$. The $\mathrm{Zn}(\mathrm{II})$-zincon complex was formed and detected in the mixing chamber. It was designed with two opposite glass windows: one for the webcam and other for the ultra-bright LED. Absorbance was calculated by the norm of the vector in the RGB space. The method had a linear range between 1.0-8.2 $\mathrm{mg} \mathrm{L}^{-1}$ with $\mathrm{R} 2=0.9998(\mathrm{n}=8)$ and limit of detection estimated as $5.7 \mu \mathrm{g} \mathrm{L} \mathrm{L}^{-1}$. The relative standard deviation (RSD) and sample throughput were estimated at $0.08 \%$ and 109 samples h$^{-1}$, respectively. Ointment commercial samples were analyzed by FB-DIC and the refference method. The results shown no statistically significant difference between them, when was applied the paired t-test at the $95 \%$ confidence level. According to green analytical chemistry (GAC) principles the FB-DIC system can be considered eco-driendly due to its low samples and reagents consumption as its low waste generation.

Keywords: Flow-batch analyser; digital image colorimetry; zinc oxide; ointments; zincon.

\section{Introduction}

Zinc oxide $(\mathrm{ZnO})$ have been used in pharmaceutical, toiletry and cosmetic industry as ointments, baby's and skin cream, toothpaste, deodorants, sunscreens, eye lotions, insulins, mouthwashes and mineral preparations with vitamins, because of its biocidal properties (as other zinc compounds). ${ }^{1}$ The importance of zinc to skin health is demonstrated in the prominent manifestation of dietary or genetically induced zinc deficiencies as dermatologic abnormalities. Low serum zinc levels generally accompany bullous pemphigoid and decubitus ulcers. ${ }^{2}$ It has shown that improvement in wound healing throught zinc exposure is not limited to oral supplementation: topically applied zinc compounds are also effective. For example, topically applied $\mathrm{ZnO}$ improves leg ulcers and has beneficial effects in occlusive dressings. ${ }^{3,4}$ Topical $\mathrm{ZnO}$ also increases the reepithelialization rate in a pig model. ${ }^{5}$ Sparingly soluble $\mathrm{ZnO}$ was found to be more effective than soluble zinc compounds. Other studies have shown that topically absorbed $\mathrm{ZnO}$ from wounds promotes the early wound-healing phase in zinc-deficient and zinc-sufficient rats, ${ }^{6}$ and topical zinc oxide promotes wounds cleansing. ${ }^{7}$

American, Brazilian and Brithish Phamacopoeias do not descibe the direct determination of $\mathrm{ZnO}$ in ointments. ${ }^{8-10}$ Due to the amphoteric properties of $\mathrm{ZnO}$ in aqueous medium, it can be indirectly determined from colorless $\left[\mathrm{Zn}\left(\mathrm{H}_{2} \mathrm{O}\right)_{6}\right]^{2+}$ or $\mathrm{ZnO}_{2}{ }^{2-}$ ions in aqueous solution depending on $\mathrm{pH}^{11}$ However, literature only describes the use of the aquo complex ion, in analytical techniques such as: titrimetry, ${ }^{8-10,12}$ gravimetry, ${ }^{12}$ Flame Atomic Absorption Spectrometry (FAAS), ${ }^{13}$ Graphite Furnace Atomic Absorption Spectrometry (GF-AAS), ${ }^{14}$ Atomic Fluorescence Spectrometry (AFS), ${ }^{15}$ Inductively Coupled Plasma Optical Emission Spectrometry (ICP-OES), ${ }^{16}$ Inductively Coupled Plasma Mass Spectrometry (ICP-MS) ${ }^{17}$ IonExchange Chromatography (IEC), ${ }^{18}$ High Performance Liquid Chromatography (HPLC), ${ }^{19}$ Gas Chromatography (GC), ${ }^{20}$ Fluorescence, ${ }^{21}$ Ultraviolet-visible Spectrometry (UV-Vis) ${ }^{22}$ and electroanalytical techniques (electrogravimetry, potentiometry, amperometry and voltammetry) ${ }^{12}$.

Although the previously mentioned techniques are sensitive and selective, most of them are also time consuming and/or require: high reagent/sample consumption and complex instruments/ professional operators. Detection plays an important role in providing good analytical 
performance. Webcam coupled to a mixing chamber (MC) in a Flow-Batch Analyzer (FBA) to perform Digital Image Detection (DID) can overcome the drawbacks ${ }^{23,24}$ above mentioned. Digital image (DI) techniques are based on digital imaging devices ${ }^{25-27}$ use to capture shots of dye solutions, and converting these images into measurable quantities from their RGB data. ${ }^{28}$ It provides good sensitivities and precisions results, as well as the low limits of detection and quantification for the analytes. ${ }^{29,30}$ FBA has advantageous characteristics of batch and flow techniques, and allows easy automation of multi-reagent and multistep procedures, remarkably high sample throughput, low reagents/samples consumption, less reagents/samples manipulation, lower cost per analysis, reduced chemical waste and fewer chances of human error. ${ }^{31,32}$

This work proposes an automatic FB-DIC system for fast and accurate zinc oxide determination in ointments using as detector RGB data from a webcam. The method is based on reaction between zinc(II) ions and zincon..$^{22}$

\section{Material and Methods}

\section{1. - treatment}

All chemicals were from analytical grade. The water was recently deionized by a Milli-Q (Millipore) system.

Stock solution of $1000 \mathrm{mg} \mathrm{L}^{-1} \mathrm{ZnO}$ (Merck, Darmstadt, Germany) was prepared dissoluting a suitable amount of the oxide in $1.0 \%\left(\mathrm{v} \mathrm{v}^{-1}\right) \mathrm{HNO}_{3}$ (Merck, Darmstadt, Germany) aqueous solution and standardized against 10.0 mmol L ${ }^{-1} \mathrm{Na}_{2}$ EDTA $\cdot 2 \mathrm{H}_{2} \mathrm{O}$ (Vetec, São Paulo, Brazil). standard solution at $\mathrm{pH}=6.0$ (hexamine) using xylenol orange as indicator. ${ }^{12}$ The calibration solutions with eight levels of $\mathrm{ZnO}\left(1.0\right.$ - $\left.8.2 \mathrm{mg} \mathrm{L}^{-1}\right)$ concentration were prepared by suitable dilution from the stock solution in water. The zincon reagent was a solution containing 1.0 mmol L-1 zincon $\left(\mathrm{C}_{20} \mathrm{H}_{15} \mathrm{~N}_{4} \mathrm{NaO}_{6} \mathrm{~S}\right)$ (Merck, Darmstadt,
Germany) and $100.0 \mathrm{mmol} \mathrm{L}^{-1}$ sodium citrate (Merck, Darmstadt, Germany) dissolved in $\mathrm{pH}=9.0$ buffer solution.

Six brands of ointments with $100 \mathrm{mg} \mathrm{g}^{-1}$ of zinc oxide nominal content were purchased from drugstores in the city of João Pessoa, Paraíba, Brazil. A suitable sample amount was placed in a porcelain crucible and gently heated by Bünsen burner, avoiding burn the sample, until was obtained a yellowish-white mass. In order to guarantee a complete mineralization, the sample was calcinated at $550{ }^{\circ} \mathrm{C}$ for 4 hours. The final residue (ashes) was solubilized in $1.0 \%\left(\mathrm{v} \mathrm{v}^{-1}\right)$ $\mathrm{HNO}_{3}$ aqueous solution up to $100 \mathrm{~mL}$ in a volumetric flask.

\subsection{Apparatus}

A FB-DIC system schematic diagram is shown in figure 1 (a). The system uses a simple lab-built MC in Teflon $®$, total internal volume of $4.0 \mathrm{~mL}$ and $7 \mathrm{~mm}$ inner diameter with two opposite glass windows. This chamber was used for mixing and homogenization. These steps are performed under mechanical stirring by a $5 \mathrm{~mm}$ magnetic bar inside the MC and a model 546410-16 (Barnstead/ Thermoline, USA) magnetic stirrer (MS).

A peristaltic pump (PP) model 78002-0 (Ismatec, Germany) was equipped with Tygon ${ }^{\circledR}$ pumping tubes and four $\left(\mathrm{V}_{\mathrm{s}}, \mathrm{V}_{\mathrm{w}}, \mathrm{V}_{\mathrm{z}}\right.$ and $\mathrm{V}_{\mathrm{D}}$ ) model EW-01540-13 (Cole Parmer, USA) three-way solenoid valves was used for fluid transport and commutation. PTFE carring tubes (Cole Parmer, USA) with $0.80 \mathrm{~mm}$ inner diameter were used as fluid transmission lines.

A webcam (WC) model Vision Wc044 (Multilaser, Brazil) was placed in front of MC's first glass window for DI acquisition and configured with gamma correction $(\gamma)=1$ in order to allow its sensor to act like common photodiode arrays found in spectrophotometers. ${ }^{23} \mathrm{WC}$ was also configured to capture 24-bit (16.7 million colors) DI at $800 \times 600$ pixels spatial resolution. The captured DI was stored in the bmp format. In the manufacture's software of the WC is possible to set operational parameters such as: gamma correction $(\gamma)$, spatial resolution of the DI and capture rate according to user convenience. (a)

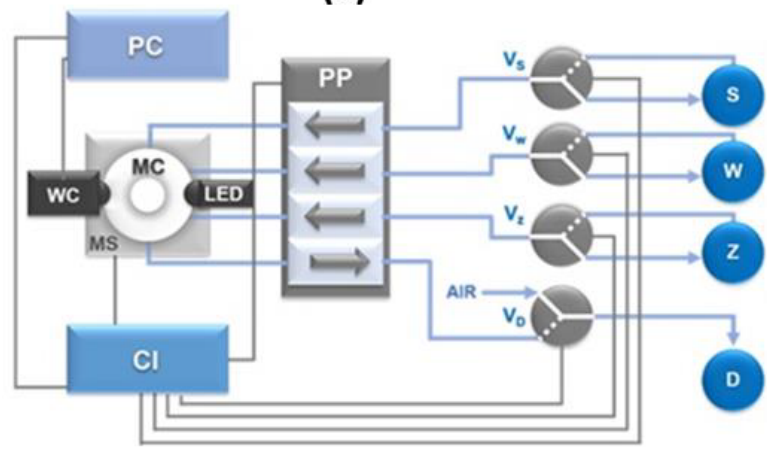

(b)

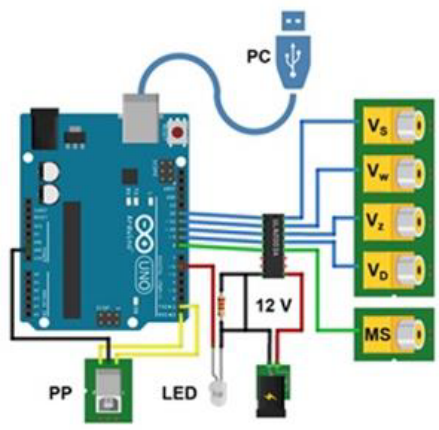

Figure 1. (a) Schematic diagram of the flow-batch assembly developed. $\mathrm{S}=$ sample/standard solution, $\mathrm{W}=$ water, $\mathrm{Z}=\mathrm{zincon}$ solution, $\mathrm{D}=$ discard, $\mathrm{VS}$, $\mathrm{VW}, \mathrm{VZ}$, and $\mathrm{VD}=$ solenoid valves, $\mathrm{PP}=$ peristaltic pump, $\mathrm{MC}=$ mixing chamber, $\mathrm{MS}=$ magnetic stirrer, $\mathrm{CI}=\mathrm{control}$ interface, $\mathrm{WC}=\mathrm{webcam}$ and $\mathrm{PC}=$ personal computer. (b) Electrical scheme of Control Interface for actuation of solenoid valves, peristaltic pump, magnetic stirrer and adjust the brightness of the LED 
A $5 \mathrm{~mm}$ ultra-bright white LED (Bluecell, USA) was placed in front of MC's second glass window to provide uniform ilumination inside it for DI acquisition.

In order to control solenoid valves, MS, PP and LED Brightness a control interface (CI), based on a model Arduino $\mathrm{UNO}^{\mathrm{TM}}$ (SparkFun Electronics, USA) microcontroller (Figure 1 (b)), was connected to a Intel® Core $^{\mathrm{TM}}$ i5-3230M CPU 2.60 $\mathrm{GHz}$, 8.00 GB RAM personal computer (PC) via USB port.

\subsection{Software and image treatment}

A lab-made software named "Flowing" was written in ActionScript 3.0 language and compiled on Adobe Air Desktop plataform (Figure 2), to manage the FB-DIC system. The software is able to actuate the solenoid valves, PP, MS, adjust the LED brightness and allow DI acquisition due to reading WC internal drivers. The DI were acquired from the reaction product's emerging inside $\mathrm{MC}$ which was illuminated by the LED.

Selecting coordinates in the digital image, the user delimits the Region of Interest (ROI) which is stored as a matrix. In this work, the ROI had $100 \times 176$ pixels. The integer average value of all RGB components of all pixels of the ROI were stored in memory for further analysis.

The analytical response was based on vector norm in the RGB tri-dimensional space. It was calculated from R, G and $\mathrm{B}$ components integer average value of ROI according to Equation $1:^{28}$

$$
\left\|\mathrm{V}_{\mathrm{RGB}}\right\|=\left(\mathrm{R}^{2}+\mathrm{G}^{2}+\mathrm{B}^{2}\right)^{1 / 2}
$$

Considering $\left\|\mathrm{V}_{\mathrm{RGB}}\right\|$ is directly proportional to radiant power of electromagnetic radiation passing through the absorbent media, since the analyte is present or not (blank solution), an expression similar to Beer-Lambert's Law for absorbance calculation can be used (Equation 2): $:^{33}$

$$
\mathrm{A}=-\log \left(\left\|\mathrm{V}_{\mathrm{RGB}}\right\|_{\mathrm{S}} /\left\|\mathrm{V}_{\mathrm{RGB}}\right\|_{\mathrm{B}}\right)
$$

Where: $\left\|\mathrm{V}_{\mathrm{RGB}}\right\|_{\mathrm{S}}$ is the norm in the RGB tri-dimensional space for standard solution/sample and $\left\|\mathrm{V}_{\mathrm{RGB}}\right\|_{\mathrm{B}}$ is the norm in the RGB tri-dimensional space for blank solution.

\subsection{Flow-batch digital image colorimetric procedure}

Aiming to better comprehend FB-DIC procedure, it was divided into analytical steps whose operational sequence can be found in table 1. It is important to emphasize that for a fast homogenization, the magnetic bar was always set in motion.

Prior to any analysis, LED, PP and MS are initially switched $\mathrm{ON}, \mathrm{V}_{\mathrm{s}}, \mathrm{V}_{\mathrm{z}}, \mathrm{V}_{\mathrm{w}}$ and $\mathrm{V}_{\mathrm{D}}$ solenoid valves are switched $\mathrm{OFF}$, and sample/standard solution, water and zincon fluids are pumped, being continuously re-circulating to their respective resevoirs (Fig. 1(a)).

The valves are simultaneously switched $\mathrm{ON}$ for $5.0 \mathrm{~s}$ to fill the channels between these valves and the MC, then immediately, $\mathrm{V}_{\mathrm{D}}$ is switched $\mathrm{ON}$ for $20.0 \mathrm{~s}$ and the $\mathrm{MC}$ is emptied. Finally, the $\mathrm{V}_{\mathrm{w}}$ was switched $\mathrm{ON}$ for $20.0 \mathrm{~s}$ and rightafter $\mathrm{V}_{\mathrm{D}}$ for $25.0 \mathrm{~s}$. This cleaning procedure should be carried out whenever there is a change in one or more fluids.

For the samples analysis $\mathrm{V}_{\mathrm{s}}$ and $\mathrm{V}_{\mathrm{z}}$, valves are simultaneously and respectively switched $\mathrm{ON}$ for 4.0 and $1.0 \mathrm{~s}$; thus filling the $\mathrm{MC}$ with $278 \mu \mathrm{L}$ and $74 \mu \mathrm{L}$ of sample and zincon fluids. After mixing, for homogenization for $3.0 \mathrm{~s}, 3 \mathrm{DI}$ are captured by the WC. Then $\mathrm{V}_{\mathrm{D}}$ is switched $\mathrm{ON}$ for $5.0 \mathrm{~s}$ and $\mathrm{MC}$ is emptied and a new cleaning procedure is carried out as previuously described.

\subsection{Reference method}

According to British pharmacopoeia, ${ }^{11}$ the reference method for zinc oxide determination in ointments is the complexometric titration described as follow: $150 \mathrm{mg}$ of the sample is dissolved in $10 \mathrm{~mL}$ of $2.0 \mathrm{~mol} \mathrm{~L}^{-1}$ acetic acid aqueous solution and $50 \mathrm{mg}$ of $1.0 \%\left(\mathrm{w} \mathrm{w}^{-1}\right)$ xylenol orange in potassium nitrate mixture is added. Solid hexamine is added until the solution color changes to violet-pink. Then added $2.0 \mathrm{~g}$ of hexamine and the solution is titrated against $\mathrm{Na}_{2} \mathrm{EDTA} \cdot 2 \mathrm{H}_{2} \mathrm{O}$ standard solution until the color violet-pink changes to yellow.

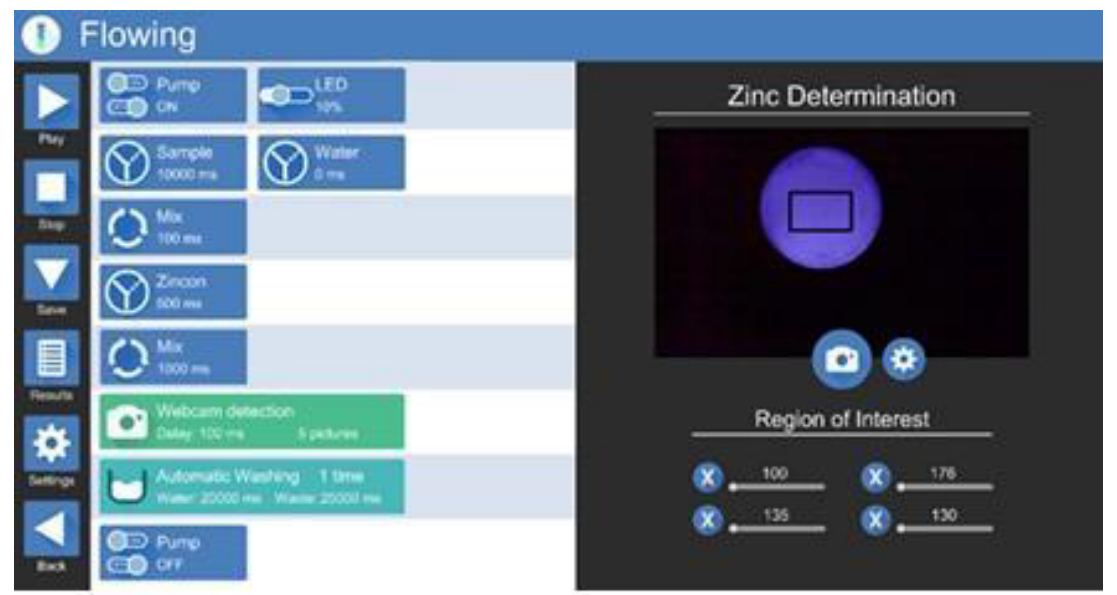

Figure 2. Software "Flowing" screenshot, developed for analysis control 
Table 1. Switching schedule of the solenoid valves in the FB-DIC procedure

\begin{tabular}{|c|c|c|c|c|c|}
\hline \multirow{2}{*}{ Step } & \multirow{2}{*}{ Procedure } & \multicolumn{4}{|c|}{ Switch ON time (s) } \\
\hline & & $\mathbf{V}_{\mathrm{S}}$ & $\mathbf{V}_{\mathrm{z}}$ & $\mathbf{V}_{\mathbf{w}}$ & $\mathbf{V}_{\text {D }}$ \\
\hline \multirow{4}{*}{ Prior to analysis } & Filling channels & 5.0 & 5.0 & 5.0 & OFF \\
\hline & First discard & OFF & $\mathrm{OFF}$ & $\mathrm{OFF}$ & 20.0 \\
\hline & First water addition & OFF & $\mathrm{OFF}$ & 15.0 & $\mathrm{OFF}$ \\
\hline & Second discard & $\mathrm{OFF}$ & OFF & $\mathrm{OFF}$ & 20.0 \\
\hline \multirow{4}{*}{ Analysis* } & Reagent/sample addition & 4.0 & 1.0 & $\mathrm{OFF}$ & OFF \\
\hline & Homogenization $(3.0 \mathrm{~s})$ & $\mathrm{OFF}$ & $\mathrm{OFF}$ & $\mathrm{OFF}$ & OFF \\
\hline & DI capture & OFF & OFF & OFF & OFF \\
\hline & Third discard & $\mathrm{OFF}$ & $\mathrm{OFF}$ & OFF & 7.0 \\
\hline \multirow{2}{*}{ Cleaning* } & Water addition & OFF & $\mathrm{OFF}$ & 8.0 & OFF \\
\hline & Fourth discard & $\mathrm{OFF}$ & $\mathrm{OFF}$ & OFF & 10.0 \\
\hline
\end{tabular}

*Only these steps are considered for estimation of sample throughput

\subsection{Zincon's method}

In slightly buffered alkaline medium (borate $\mathrm{pH}=$ 9.0-9.3), zincon (2-carboxy-2'-hydroxy-5'-sulfoformazylbenzene monosodium salt, $\mathrm{C}_{20} \mathrm{H}_{15} \mathrm{~N}_{4} \mathrm{NaO}_{6} \mathrm{~S}$ ) reacts with $\mathrm{Zn}$ (II) ions yielding a blue complex (Equation 3 ) with maximum absorption at $618 \mathrm{~nm}\left(\varepsilon=2.723 \times 10^{4} \mathrm{~L} \mathrm{~mol}^{-1}\right.$ $\left.\mathrm{cm}^{-1}\right) \cdot{ }^{34}$ Zincon is a tetradentate ligand and the stoichiometry of the complex is 1:1. In the complex, $\mathrm{Zn}(\mathrm{II})$ ion presents an tetrahedral geometry (coordination number $=4)^{35}$

$\left(\mathrm{C}_{20} \mathrm{H}_{15} \mathrm{~N}_{4} \mathrm{O}_{6} \mathrm{~S}\right) \cdot(\mathrm{aq})+\mathrm{Zn}^{2+}(\mathrm{aq})+3 \mathrm{H}_{3} \mathrm{O}^{+}(\mathrm{aq})+\left[\mathrm{Zn}-\left(\mathrm{C}_{20} \mathrm{H}_{12} \mathrm{~N}_{4} \mathrm{O}_{6} \mathrm{~S}\right)\right]^{2-(a q)}$

At $\mathrm{pH}=9.0-9.3$, zincon form sTable complexes with $\mathrm{Zn}(\mathrm{II}), \mathrm{Cu}(\mathrm{II}), \mathrm{Ni}(\mathrm{II}), \mathrm{Co}(\mathrm{II}), \mathrm{Pb}$ (II), $\mathrm{Cd}$ (II) and $\mathrm{Hg}$ (II) ions. ${ }^{34}$ In order to guarantee the zincon and $\mathrm{Zn}$ (II) ions reaction specificity, sodium citrate was used as masking agent for $\mathrm{Cu}(\mathrm{II}), \mathrm{Ni}(\mathrm{II}), \mathrm{Co}(\mathrm{II}), \mathrm{Pb}$ (II), $\mathrm{Cd}(\mathrm{II})$ and $\mathrm{Hg}$ (II) ions.

\section{Results and Discussion}

\subsection{Optimization of experimental conditions}

Two factors were evaluated to increase sensitivity and reproducibility of the analytical response; aiming lower values of limit of detection (LOD) and limit of quantification (LOQ) and also increase sample throughput: the zincon concentration and the reaction time. For this, a $1.0 \mathrm{mg} \mathrm{L}^{-1}$ $\mathrm{ZnO}$ standard solution was used.

The selection criterion of the best conditions was the highest absorbance, with the lowest absolute standard deviation $\mathrm{SD}(\mathrm{n}=3)$. Initially, to determinate the best zincon concentration, the FB-DIC procedure used $10.0 \mathrm{~s}$ reaction time. Since the best zincon concentration, the best reaction time was determined. Results are in table. It shows the best combination for the definitive FB-DIC procedure were 1.0 mmol L-1 zincon and $3.0 \mathrm{~s}$ reaction time.
3.2. Analytical curve and performance of the FB-DIC system

A linear relationship between analytical response (absorbance) and the $\mathrm{ZnO}$ concentration in the calibration solutions was observed. The data verification was carried out by using ordinary least squares (OLS) method which yielded the confidence intervals of the calibration model parameters, $\hat{\mathrm{y}}=\left(\alpha \pm t_{22} \mathrm{~s}(\alpha)\right)+\left(\beta \pm t_{22} \mathrm{~s}(\beta)\right) \mathrm{X}$ at the $95 \%$ confidence level: Absorbance $=(0.0088 \pm 0.0097)+(0.0955$ $\pm 0.0004) \mathrm{C}$; where $\mathrm{C}$ is the concentration of $\mathrm{ZnO}$ in $\mathrm{m} \mathrm{L}^{-1}$.

The model determination coefficient $\left(\mathrm{R}^{2}\right)$ revealed the linear model could describe $99.98 \%$ of data variance. An analysis in the confidence intervals of the built model coefficients revealed that to linear coefficient, it contains the "zero" and consequently did not have statistical significance. ${ }^{36}$ As a result, the data variance could be described only with the angular coefficient (slope) which had statistical significance.

Although slope describes $99.98 \%$ of data variance, information about the existence of systematic errors cannot be assessed. For this, is necessary to implement an analysis of variance (ANOVA) which consists in two $F$-tests: the first one evaluates the lack of fit while the second evaluates the significance of regression. ${ }^{37}$

In order to implement the ANOVA, the analytical curves were constructed based on three genuine repeated measurements in the eight levels of concentration and regression values, residual, lack of fit and pure error were calculated using the mean squares (MS) presented in Table 3.

The $F$-tests for lack of fit consists in the comparison of the $\mathrm{MS}_{\text {lack of fit }} / \mathrm{MS}_{\text {pure error }}$ ratio with the point of $F$-distribution (with the same degrees of freedom at a defined confidence level). According to Table 3, there is no evidence of systematic errors in the linear model since the $\mathrm{MS}_{\text {lack }}$ of fit $/ \mathrm{MS}_{\text {pure error }}$ ratio is much smaller than the point of $F$-distribution $\left(F_{\text {critical }}\right)$ at a $95 \%$ confidence level with equivalent freedom degrees (6 and 16, respectively).

The $F$-tests for regression significance consist comparing $\mathrm{MS}_{\text {regression }} / \mathrm{MS}_{\text {residual }}$ ratio with $F$-distribution point (with 
Flow-batch digital image colorimetric system to zinc oxide determination in ointments

Table 2. Absorbance values for different zincon concentrations and reaction times

\begin{tabular}{cccc}
\hline Zincon $\left(\mathbf{m m o l ~ \mathbf { L } ^ { - 1 }}\right)$ & Absorbance \pm SD & Reaction time $(\mathbf{s})$ & Absorbance \pm SD \\
\hline 0.1 & $0.026 \pm 1.1 \times 10^{-3}$ & 0.5 & $0.020 \pm 1.3 \times 10^{-3}$ \\
0.5 & $0.057 \pm 1.8 \times 10^{-3}$ & 1.5 & $0.057 \pm 1.8 \times 10^{-3}$ \\
1.0 & $0.108 \pm 5.0 \times 10^{-4}$ & 2.5 & $0.089 \pm 1.4 \times 10^{-3}$ \\
2.0 & $0.106 \pm 1.3 \times 10^{-3}$ & 3.0 & $0.108 \pm 5.0 \times 10^{-4}$ \\
3.0 & $0.104 \pm 2.0 \times 10^{-3}$ & 5.0 & $0.108 \pm 1.0 \times 10^{-3}$ \\
4.0 & $0.106 \pm 1.6 \times 10^{-3}$ & 10.0 & $0.108 \pm 1.0 \times 10^{-3}$ \\
\hline
\end{tabular}

Table 3. Analysis of variance for the fit of a linear model $(\hat{y}=\boldsymbol{\alpha}+\boldsymbol{\beta X})$ of the analytical curve

\begin{tabular}{cccc}
\hline \multicolumn{4}{c}{ Sum and mean aquare } \\
\hline Source & Sum square (SS) & Degrees of freedom & Mean square (MS) \\
\hline Regression & 1.14 & 1 & 1.14 \\
Residual & $1.23 \times 10^{-4}$ & 22 & $5.57 \times 10^{-6}$ \\
Lack of fit & $2.59 \times 10^{-6}$ & 6 & $4.31 \times 10^{-7}$ \\
Pure error & $1.20 \times 10^{-4}$ & 16 & $7.50 \times 10^{-6}$ \\
\hline \multicolumn{4}{c}{$\boldsymbol{F}$-test for lack of fit } \\
\hline $\mathrm{MS}_{\text {lack of fit }} / \mathrm{MS}_{\text {pure error }}$ & $5.74 \times 10^{-2}$ & $2.74(6,16)^{*}$ \\
\hline $\mathrm{MS}_{\text {regression }} / \mathrm{MS}_{\text {residual }}$ & $\boldsymbol{F}$-test for significance of regression \\
\hline
\end{tabular}

*The numbers between parentheses indicate the respectives degrees of freedom.

the same freedom degrees at a defined confidence level). According to Table 3 , the regression is highly significant, since the $\mathrm{MS}_{\text {regression }} / \mathrm{MS}_{\text {residual }}$ ratio is higher than the $F$-distribution $\left(F_{\text {critical }}\right)$ point at $95 \%$ confidence level with equivalent freedom degrees ( 1 and 22, respectively).

Since the analytical curve did not present lack of fit and the regression highly significant, it can be considered partially validated and able to estimate $\mathrm{ZnO}$ concentration in commercial samples of ointment.

After validating the analytical curve is possible to evaluate the FB-DIC system analytical performance. This evaluation Figures the merit, such as: sensitivity, LOD, LOQ, sample throughput and relative standard deviation (RSD) of the analytical curve were chosen.

According to IUPAC recommendation, ${ }^{38} \mathrm{LOD}$ and LOQ were estimated from thirty measurements of the blank using Equations 4 and 5, respectively:

$$
\begin{aligned}
& \mathrm{LOD}=3 \mathrm{~s}_{\mathrm{b}} / \beta \\
& \mathrm{LOD}=10 \mathrm{~s}_{\mathrm{b}} / \beta
\end{aligned}
$$

Where $s_{b}$ is the standard deviation of the blank and " $\beta$ " is the slope of the analytical curve based on Equation 2 and estimated by OLS method. The LOD and LOQ values were estimated in 5.7 and $19.1 \mu \mathrm{g} \mathrm{L}^{-1}$, respectively.

The RSD of the analytical curve was estimated in $0.06 \%$ and the total time for analysis of a single sample is $33.0 \mathrm{~s}$ (Table 1), allowing to analyze up to 109 sample $\mathrm{h}^{-1}$. This high value may be attributed to the integrated detection of the WC provided by the glass window.

\subsection{Analytical determinations}

After optimizing experimental conditions, validating the analytical curve and estimation of the figures of merit, the FBDIC system was applied in $\mathrm{ZnO}$ determination in commercial samples of ointments. As presented in table 4 the FB-DIC and the titrimetric method (reference) have yielded similar results. In fact, the paired $t$-test at the $95 \%$ confidence level was applied and revealed no statistic significant differences between the results.

The FB-DIC system presented a better precision as seen the lower value of overall relative standard deviation (R.S.D.) $(\mathrm{n}=3)$. This satisfactory precision was ascribed to the multivariate nature of the monitored signal in digital image-based determinations. ${ }^{26}$

Table 5 presents selected analytical features of the proposed FB-DIC and other automated systems for determination of zinc species with zincon as colorimetric reagent described in literature..$^{39,40}$

In general, the FB-DIC presented satisfactory parameters such as LOD, overall R.S.D., working range, sample throughput, in-line preparation of calibration solutions, elimination of the carrier fluid, and no associated fluid dispersion (which yields loss of sensitivity), when compared with other flow systems.

\section{Conclusions}

In this work, a FB-DIC system for zinc oxide determination in ointment samples, using the zincon as colorimetric reagent, was developed. The rapid zinc(II)-zincon complex formation allowed 
Table 4. Results of $\mathrm{ZnO}$ determinations using FB-DIC and titrimetric method." por "Table 4. Results (in $\mathrm{mg}$ g-1) of $\mathrm{ZnO}$ determinations using FB-DIC and titrimetric method.

\begin{tabular}{ccc}
\hline Sample & FB-DIC & Titrimetry \\
\hline$(1)$ & $112.9 \pm 2.9 \times 10^{-1}$ & $113.1 \pm 9.0 \times 10^{-1}$ \\
$(2)$ & $135.1 \pm 2.8 \times 10^{-1}$ & $134.8 \pm 8.7 \times 10^{-1}$ \\
$(3)$ & $131.7 \pm 6.3 \times 10^{-2}$ & $132.0 \pm 8.8 \times 10^{-1}$ \\
$(4)$ & $110.1 \pm 6.9 \times 10^{-1}$ & $109.7 \pm 9.0 \times 10^{-1}$ \\
$(5)$ & $129.8 \pm 3.3 \times 10^{-1}$ & $130.0 \pm 8.7 \times 10^{-1}$ \\
$(6)$ & $91.7 \pm 1.9 \times 10^{-1}$ & $91.4 \pm 8.7 \times 10^{-1}$ \\
Overall R.S.D. (\%) & 0.36 & 0.74 \\
\hline
\end{tabular}

Table 5. Analytical characteristics of the proposed FB-DIC and other automated systems for determination of zinc species with zincon.

\begin{tabular}{lccc}
\hline Parameter & FB-DIC & FIAb 39 & FIAb 40 \\
\hline Detector & Webcam & Spectrophotometric & Spectrophotometric \\
Integrated detection & Present & Absent & Absent \\
Zinc specie(s) determined & ZnO & Metalic Zn, Zn(II) ions & Metallic Zn \\
Analysed samples & Ointments & Waters, alloys and insulin formulations & Brass \\
Working range (mg L-1) & $8.0 \times 10-1-6.6 \mathrm{a}$ & $1.0-10.0$ & $1.4 \times 10-1-8.0$ \\
Sensitivity (L mg-1) & $0.1194 \mathrm{a}$ & 0.0716 & 0.0640 \\
LOD $(\mu \mathrm{g}$ L-1) & $4.6 \mathrm{a}$ & 50.0 & 40.0 \\
Analytical curve overall R.S.D. $(\%)$ & $0.08(\mathrm{n}=24)$ & $0.9(\mathrm{n}=50)$ & $1.8(\mathrm{n}=11)$ \\
Sample throughput (sample h-1) & 109 & 80 & 43 \\
Sample consumption $(\mu \mathrm{L})$ & 278.0 & 300.0 & 100.0 \\
Reagent consumption $(\mathrm{mL})$ & $7.4 \times 10-2$ & 1.3 & 3.65 \\
Carrier fluid & Absent & Present & Present \\
Waste generation $(\mathrm{mL})$ & $3.51 \times 10-1$ & 1.6 & 3.75 \\
Preparation of calibration solutions & In-line & Off-line & Off-line \\
\hline
\end{tabular}

${ }^{a}$ The values were converted from $\mathrm{ZnO}$ to $\mathrm{Zn}$ for a fair comparison.. ${ }^{\mathrm{b}}$ Flow injection analysis.

precise measurements within $3.0 \mathrm{~s}$. The LED ilumination inside MC allowed direct DI acquisition and increased the efficiency of this system. The reagent optimized concentration in $1.0 \mathrm{mmol}$ $\mathrm{L}^{-1}$ allowed sensitivity to identification of small changes in zinc(II)-zincon complex color. Mechanical perturbation from magnetic bar spinning inside the MC under LED illumination did not influence the results.

The webcam essentially acted as a photodiode array generating DIs with linear RGB data, suitable for the simple absorbance model based on the RGB norm vector. The proposed system also generates low amounts of waste (lower than $2.0 \mathrm{~mL}$ per test), when compared with titration and other methods described in the literature. The low levels of reagent consumption and waste generation in the proposed method qualify the analytical procedure as eco-friendly according to green analytical chemistry (GAC) principles. ${ }^{41}$

\section{Acknowledgements}

The authors would like to thank the Brazilian agencies CNPq and CAPES for research fellowships and scholarships.

\section{References}

1. Matíes, R.; Jiménez, F.; Arias, J. J.; Román, M.; Spectrofluorimetric determination of zinc with 1,2,4-trihydroxyanthraquinone in pharmaceutical preparations. Analytical Letters 1997, 30, 2059. [CrossRef]

2. Tasaki, M.; Hanada, K.; Hashimoto, I.; Analyses of serum copper and zinc levels and copper/zinc rations in skin diseases. The Journal of Dermatology 1993, 20, 21. [CrossRef] [PubMed]

3. Stromberg, H. -E.; Ågren, M. S.; Topical zinc oxide treatment improves arterial and venous leg ulcers. British Journal of Dermatology 1984, 111, 461. [CrossRef] [PubMed]

4. Rittenhouse, T.; The management of lower-extremity ulcers with zinc-saline wet dressings versus normal saline wet dressings. Advances in Therapy 1996, 13, 88. [PubMed]

5. Agren, M. S.; Influence of two vehicles for zinc oxide on zinc absorption through intact skin and wounds. Acta Dermato Venereologica 1991, 71, 153. [PubMed]

6. Hallmans, G.; Lasek, J.; The effect of topical zinc absorption from wounds on growth and the wound healing process in zincdeficient rats. Scandinavian Journal of Plastic and Reconstructive Surgery 1984, 19, 119. [CrossRef] [PubMed]

7. Agren, M. S.; Percutaneous absorption of zinc from zinc oxide applied topically to intact skin in man. Dermatologica 1990, 180, 36. [CrossRef] [PubMed]

8. The United States Pharmacopoeia-National Formulary, USP-NF XXIII.

9. Brasil; Farmacopeia brasileira, Vol. 2, 5a ed.,ANVISA: Brasília, 2010.

10. British Pharmacopoeia Commission; British Pharmacopoeia 2012, The Stationery Office: London, 2012.

11. Patnaik, P.; Handbook of inorganic chemicals, McGraw-Hill: New York, 2003 
12. Jeffery, G. H.; Basset, J.; Mendhan, J.; Denney, R. C.; Vogel's textbook of quantitative chemical analysis, 5th ed., Longman Scientific and Technical: London, 1989.

13. Soylak,M.; Tuzen, M.; Souza, A. S.; Korn, M. das G. A.; Ferreira, S. L. C.; Optimization of microwave assisted digestion procedure for the determination of zinc, copper and nickel in tea samples employing flame atomic absorption spectrometry. Journal of Hazardous Materials 2007, 149, 264. [CrossRef] [PubMed]

14. Huang, S.-D.; Shih, K.-Y.; Direct determination of zinc in seawater by graphite furnace atomic absorption spectrometry. Spectrochimica Acta Part B: Atomic Spectroscopy 1995, 50, 837. [CrossRef]

15. Mansfield, J. M.; Winefordner, J. D.; Veillon, C.; High sensitivity determination of zinc, cadmium, mercury, thallium, gallium and indium by atomic fluorescence flame spectrometry. Analytical Chemistry 1965, 37, 1049. [CrossRef]

16. Chochorek, A.; Bobrowski, A.; Kiralyova, Z.; Mocak, J.; ICP-OES determination of select metals in surface water - A metrological study. Polish Journal of Environmental Studies 2010, 19, 59. [Link]

17. Hsiung, C. S.; Andrade, J. D.; Costa, R.; Ash, K. O.; Minimizing interferences in the quantitative multielement analysis of trace elements in biological fluids by inductively coupled plasma mass spectrometry. Clinical Chemistry 1997, 43, 2303. [CrossRef]

18. Maier R. H.; Bullock, J. S.; Determination of zinc in plant materials using ion-exchange chromatography. Analytica Chimica Acta 1958, 19, 354. [CrossRef]

19. Kondoh,Y.; Takano, S.; Determination of zinc pyrithione in cosmetic products by high-performance liquid chromatography with pre-labelling. Journal of Chromatography A 1987, 408, 255. [CrossRef] [PubMed]

20. Becchi, M.; Perret, F.; Carraze, B.; Beziau, J. F.; Michel, J. P.; Structural determination of zinc dithiophosphates in lubricating oils by gas chromatography-mass spectrometry with electron impact and electron-capture negative ion chemical ionization. Journal of Chromatography A 2001, 905, 207. [CrossRef] [PubMed]

21. Campañó, R.; Hernández-Cassou, S.; Prat, M. D.; GarcíaBeltrán, L.; Flow-injection determination of zinc by fluorescence spectrometry. Analytica Chimica Acta 1991, 255, 325. [CrossRef]

22. Clesceri, L. S.; Greenberg, A. E.; Eaton, A. D.; Standard methods for the examination of water and wastewater, 20th ed., American Public Health Association: Washington, 1998.

23. Almeida-Junior, P. L.; Bonfim, T. Th. F.; Cunha, F. A. S.; Lima, K. M. G.; Aquino, J. S.; Almeida, L. F.; A rapid, sensitive and green analytical method for the determination of sulfite in vinegars using pararosaniline reaction with image detection. Analytical Methods, 2018, 10, 448. [CrossRef]

24. Andrade, R. A. N.; Cunha, F. A. S.; Andrade, S. I. E.; Almeida Junior, P. L.; Navarro, L. A. O.; Lyra, W. S.; Pessoa, A. G. G.; Lima, R. A. C.; Araujo, M. C. U.; A digital capture movie-based robotized flow-batch luminometer for in-line magnetic nanoparticle solid phase extraction and chemiluminescent measurement. Microchemical Journal 2019, 153, 104387. [CrossRef]

25. García, A.; Erenas, M. M.; Marinetto, E. D.; Abad, C. A.; OrbePaya, I.; Palma, A. J.; Capitán-Vallvey, L. F.; Mobile phone platform as portable chemical analyzer. Sensors and Actuators B: Chemical 2011, 156, 350. [CrossRef]

26. Gaiao, E. N.; Martins, V. L.; Lyra, W. S.; Almeida, L. F.; Silva, E. C.; Araújo M. C. U.; Digital image-based titrations. Analytica Chimica Acta 2006, 570, 283. [CrossRef] [PubMed]
27. Paciornik,S.;Yallouz, A. V.; Campos, R. C.; Gannerman, D.; Scanner image analysis in the quantification of mercury using spot-tests. Journal of the Brazilian Chemical Society 2006, 17, 156. [CrossRef]

28. Oliveira, H. J. S.; Almeida-Junior, P. L.; Sampaio, B. A.; Fernandes, J. P. A.; Pessoa-Neto, O. D.; Lima, E. A.; Almeida, L. F.; A handheld smartphone-controlled spectrophotometer based on hue to wavelength conversion for molecular absorption and emission measurements. Sensors and Actuators B: Chemical 2017, 238, 1084. [CrossRef]

29. Lyra, W. S.; Santos, V. B.; Dionízio, A. G. G.; Martins, V. L.; Almeida, L. F.; Gaião E. N.; Diniz, P. H. G. D.; Silva, E. C.; Araujo, M. C. U.; Digital image-based flame emission spectrometry. Talanta 2009, 77, 1584. [CrossRef] [PubMed]

30. Lyra, W. S.; Sanches, F. A. C.; Cunha, F. A. S.; Diniz, P. H. G. D.; Lemos, S. G.; Silva, E. C.; Araujo, M. C. U.; Indirect determination of sodium diclofenac, sodium dipyrone and calcium gluconate in injection drugs using digital image-based (webcam) flame emission spectrometric method. Analytical Methods 2011, 3, 1975. [CrossRef]

31. Cunha, F. A. S.; Sousa, R. A.; Harding, D. P.; Cadore, S.; Almeida, L. F.; Araújo, M. C. U.; Automatic microemulsion preparation for metals determination in fuel samples using a flow-batch analyzer and graphite furnace atomic absorption spectrometry. Analytica Chimica Acta 2012, 727, 34. [CrossRef] [PubMed]

32. Cunha, F. A. S.; Pereira, A. S. G.; Fernandes, J. P. A.; Lyra, W. S.; Araújo, M. C. U.; Almeida, L. F.; Automated single-phase liquidliquid extraction for determination of $\mathrm{Cr}(\mathrm{VI})$ using graphite furnace atomic absorption spectrometry without wet digestion of samples. Food Analytical Methods 2017, 10, 921. [CrossRef]

33. Benedetti, L. P. S.; Santos, V. B.; Silva, T. A.; Benedetti-Filho, E.; Martins, V. L.; Fatibello-Filho, O.; A digital image analysis method for quantification of sulfite in beverages. Analytical Methods 2015, 7, 7568. [CrossRef]

34. Kocyła, A.; Pomorski, A.; Krężel, A.; Molar absorption coefficients and stability constants of zincon metal complexes for determination of metal ions and bioinorganic application. Journal of Inorganic Biochemistry 2017, 176, 53. [CrossRef] [PubMed]

35. Mabrouk,H. E.; Gaber, M.; El-Sonbati, A. Z.; El-Hefnawey, G. B.; Direct electrochemical synthesis of cobalt, nickel, copper, zinc, cadmium, tin and lead complexes. Transition Metal Chemistry 1992, 17, 1. [CrossRef]

36. Bruns, R. E.; Scarminio, I. S.; Barros Neto, B.; Statistical design - Chemometrics, 1st ed., Elsevier: Amsterdam, 2006.

37. Draper, N. R.; Smith, H.; Applied regression analysis, 3rd ed., Wiley: New York, 1998.

38. IUPAC.; Nomenclature, symbols, units and their usage in spectrochemical analysis - II. Data interpretation. Pure and Applied Chemistry 1976, 45, 99. [CrossRef]

39. Koupparis, M. A.; Anagnostopoulou, P. I.; Automated flow injection spectrophotometric determination of zinc using zincon: applications to analysis of waters, alloys and insulins formulations. Analyst 1986, 111, 1311. [CrossRef] [PubMed]

40. Richter, P.; Toral, M. I.; Fuenzalida, E.; Richter, P.; Tapia, A. E.; Flow injection photometric determination of zinc and copper with zincon based on the variation of the stability of complexes with pH. Analyst 1997, 122, 1045. [CrossRef] [PubMed]

41. Armenta, S.; Garrigues, S.; de la Guardia, M.; Green analytical chemistry. Trends in Analytical Chemistry 2008, 27, 497. [CrossRef] 